\title{
Use of disease-modifying drugs (tocilizumab, tofacitinib, and baricitinib-a biological or synthetic target specific) in patients hospitalized with COVID-19
}

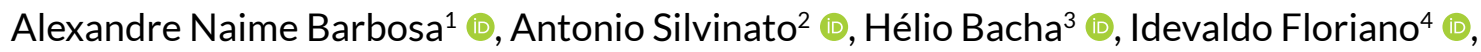 \\ Suzana Tanni ${ }^{5}$ (D), Wanderley Bernardo $2,6 *$ (1)
}

The Guidelines Project, an initiative of the Brazilian Medical Association, aims to combine information from the medical field to standardize how to conduct and to assist in the reasoning and decision-making of doctors. The information provided by this project must be critically evaluated by the physician responsible for the conduct that will be adopted, depending on the conditions and the clinical condition of each patient. Guideline conclusion: November 2021.

Societies: Associação Médica Brasileira, Sociedade Brasileira de Infectologia and Sociedade Brasileira de Pneumologia e Tisiologia.

\section{INTRODUCTION}

In November 2019, the world was surprised with another pandemic that has spread with great speed, causing enormous loss of life across humanity. The etiologic agent is a virus, called coronavirus, belonging to the Coronaviridae family, whose genetic material is RNA. Being known to cause flu and enteric syndromes since 2003, coronavirus has been associated with severe acute respiratory syndrome (SARS) in Asia and the Middle East respiratory syndrome (MERS) in the Middle East in 2013. Numerous immunobiological drugs with antiviral action and inhibitors of the inflammatory cascade, linked to the physiopathogenesis of acute respiratory syndrome caused by coronaviruses (SARS-CoV-2), have been researched and tested to minimize damage in infected patients.

The benefit of glucocorticoids in critically ill patients supports the concept that an excessive host inflammatory response is responsible for much of the severe disease and death of COVID-19.

The advanced stage of COVID-19 is associated with high levels of C-reactive protein (CRP) and cytokines, including interleukin-1 (IL-1) and IL-6. IL-6 is a pleiotropic pro-inflammatory cytokine produced by several types of cells, including lymphocytes, monocytes, and fibroblasts. SARS-CoV-2 infection induces a dose-dependent production of IL- 6 from bronchial epithelial cells. In some patients, this response becomes a nonspecific inflammation, a "cytokine storm," involving edema and infiltration of inflammatory cells in the lungs, leading to hypoxia and respiratory failure, being considered an important cause of disease progression and even death of patients with COVID-19. These cases are among the most serious.

The recombinant monoclonal antibody tocilizumab (TCZ) blocks IL-6 receptors and is approved for use in patients with rheumatologic disorders and cytokine release syndrome induced by chimeric T-cell antigen receptor therapy.

Tofacitinib is a potent selective inhibitor of the Janus kinases (JAK) family. In enzymatic assays, tofacitinib inhibits JAK1, JAK2, JAK3, and, to a lesser extent, tyrosine kinase (TyK2). It also has a high degree of selectivity for other kinases in the human genome. In human cells, tofacitinib preferentially inhibits signaling from heterodimeric cytokine receptors associated with JAK3 and/or JAK1, with functional selectivity for cytokine receptors that signal through JAK2 pairs. The inhibition of JAK1 and JAK3 by tofacitinib attenuates the signaling of interleukins (e.g., IL-2, IL-4, IL-6, IL-7, IL-9, IL-15, and IL-21) and interferon types I and II, which results in modulation immune and inflammatory responses, with potential to reduce the damage of SARS-CoV-19.

\footnotetext{
${ }^{1}$ Universidade Estadual Paulista, Faculdade de Medicina de Botucatu, Departamento de Infectologia - Botucatu (SP), Brazil.

${ }^{2}$ Associação Médica Brasileira, Medicina Baseada em Evidências - São Paulo (SP), Brazil.

${ }^{3}$ Hospital Israelita Albert Einstein - São Paulo (SP), Brazil.

${ }^{4}$ Cooperativa Baixa Mogiana, Medicina Baseada em Evidências - Mogi Guaçu (SP), Brazil.

${ }_{5}^{5}$ Universidade Estadual Paulista, Faculdade de Medicina de Botucatu, Departamento de Clínica Médica, Disciplina de Pneumologia - Botucatu (SP), Brazil.

ŁUniversidade de São Paulo, Faculdade de Medicina - São Paulo (SP), Brazil.

*Corresponding author:wmbernardo@usp.br

Conflicts of interest: the authors declare there is no conflicts of interest. Funding: none.

Received on November 19, 2021. Accepted on November 19, 2021.
} 
Baricitinib is a small molecule reversible JAK1 and JAK2 inhibitor with dual anticytokine and antiviral activity suggested against SARS-CoV-2 infection. It restricts excessive inflammatory signaling and blunts interferon-mediated induction of interferon response genes that include in at least some tissues the viral angiotensin-converting enzyme 2 (ACE2) receptor. Baricitinib inhibits the intracellular signaling pathway of cytokines known to be elevated in severe COVID-19, including IL-2, IL-6, IL-10, interferon- $\gamma$, and granulocyte-macrophage colony-stimulating factor, and acts against SARS-CoV-2 through the impairment of AP2-associated protein kinase 1, preventing SARS-CoV-2 cellular entry and infectivity.

\section{OBJECTIVE}

The aim of this systematic review was to evaluate the efficacy and safety of treatment with disease-modifying drugs, whether biological (TCZ) or synthetic target specific (tofacitinib and baricitinib), in patients with COVID-19.

\section{METHODS}

The clinical question is: What is the impact, on clinical outcomes that matter, of TCZ, tofacitinib, and baricitinib in the treatment of patients hospitalized with COVID-19 compared to conventional treatment?

The eligibility criteria of this study are as follows:

1. Adult patient hospitalized with COVID-19

2. Treatment with TCZ or tofacitinib or baricitinib plus standard therapy compared to conventional therapy with or without placebo

3. Outcomes-death (any cause) or mechanical ventilation (MV) or hospital discharge or adverse events

4. Intermediate outcomes excluded

5. Phase 3 randomized clinical trial

6. No period or language limit

7. Full-text available for access

8. Tracking time: 28 days minimum

9. No history of drug use

The search for evidence was performed in the virtual scientific information databases Medline, Embase, and ClinicalTrials.gov, using the search strategy (COVID OR COV OR CORONAVIRUS OR SARS) AND (tocilizumab OR tofacitinib OR baricitinib) AND random*. Searches in these databases were carried out until the month of September 2021. We imposed no restrictions regarding date of publication, language, or full-text availability.
Two independent researchers selected and extracted the data from the included studies. First, the articles were selected based on the title and abstract. Second, full texts were evaluated to include or exclude the studies; disagreements were resolved by consensus.

The following data were extracted from the studies: author's name and year of publication, population studied, intervention and comparison methods, absolute number of outcome events, and follow-up time.

The measures used to express benefit and harm varied according to outcomes expressed as continuous variables (mean and standard deviation) or expressed as categorical variables (absolute number of events). The results are expressed as mean difference and standard deviation for continuous variables and as absolute risks, risk differences $(\mathrm{RD})$, and the number needed to treat $(\mathrm{NNT})$ or number needed to harm $(\mathrm{NNH})$ for categorical variables. The confidence level used is $95 \%$. If there are common outcomes among the included studies, the results will be expressed through meta-analysis, using the RevMan version 5.4 software ${ }^{1}$.

If there is a possibility of performing the meta-analysis, the adopted analysis model varies according to the level of heterogeneity, being fixed for levels of heterogeneity $<50 \%$ and random when $\geq 50 \%$.

Randomized clinical trials will have their risk of bias analyzed using the RoB version 2 instrument ${ }^{2}$, being considered as very serious, serious, or nonserious. The quality of evidence will be assessed by the GRADE systemGrading of Recommendations Assessment, Development and Evaluation using the GRADEpro software ${ }^{3}$, with grading of the quality of evidence as very low, low, moderate, or high.

\section{RESULTS}

In the search for evidence, 229, 32, and 72 papers were retrieved in Medline, Embase, and ClinicalTrials.gov, respectively. Of these, meeting the eligibility criteria, 11 studies were selected ${ }^{4-14}, 9$ evaluating the use of $\mathrm{TCZ}^{4-12}, 1$ the use of tofacitinib ${ }^{13}$, and 1 the use of baricitinib ${ }^{14}$, in the treatment of patients hospitalized with COVID-19, in comparison with conventional therapy [standard care (SC)] with or without placebo (Figure 1).

The results are expressed in the following order and form:

(1) TCZ, (2) tofacitinib, and (3) baricitinib, including the synthetic description of the studies included, the risk of bias, and the analysis of their results (also expressed as "forest plots" in the presence of meta-analysis). 


\section{TOCILIZUMAB}

A total of 6,489 inpatients with moderate/severe COVID-19, who were undergoing therapy with TCZ $(n=3,358)$ compared to conventional treatment with or without placebo $(n=3,131)$, and who were followed to measure the outcomes of death, MV, hospital discharge, and adverse events within 28-30 days of admission were included.

Regarding the risk of bias of the 9 studies included, only 3 of them were double-blind and had evaluator blinding; two had losses $>20 \%$; one did not perform sample calculation and analysis by ITT; and two had early interruption, therefore, we considered the overall risk of bias of the studies to be moderate.
The nine studies evaluated the outcome of death from any cause (Figure 2); five MV studies (Figure 3), six hospital discharges (Figure 4), and eight serious adverse events (Figure 5); all outcomes in a follow-up of up to 28-30 days.

Nine studies allowed us to assess the death outcome in 28-30 days, with a total of 6,489 participants, and comparing the $\mathrm{TCZ}+\mathrm{SC}$ with SC alone, there was no significant difference [absolute risk reduction (RRA) $=-0.01 ; 95 \% \mathrm{CI}-0.04$ to 0.03 ; $\left.\mathrm{I}^{2}=60 \%\right]$ (Figure 2). This results in low quality of evidence.

Six studies allowed us to evaluate the outcome of MV in 28-30 days, with a total of 3,062 participants, and comparing $\mathrm{TCZ}+\mathrm{SC}$ with $\mathrm{SC}$ alone, TCZ reduces the risk of $\mathrm{MV}$ by $2 \%$ (RRA $=-0.02,95 \% \mathrm{CI}-0.04$ to $\left.-0.00 ; \mathrm{I}^{2}=0 \%\right)$, requiring

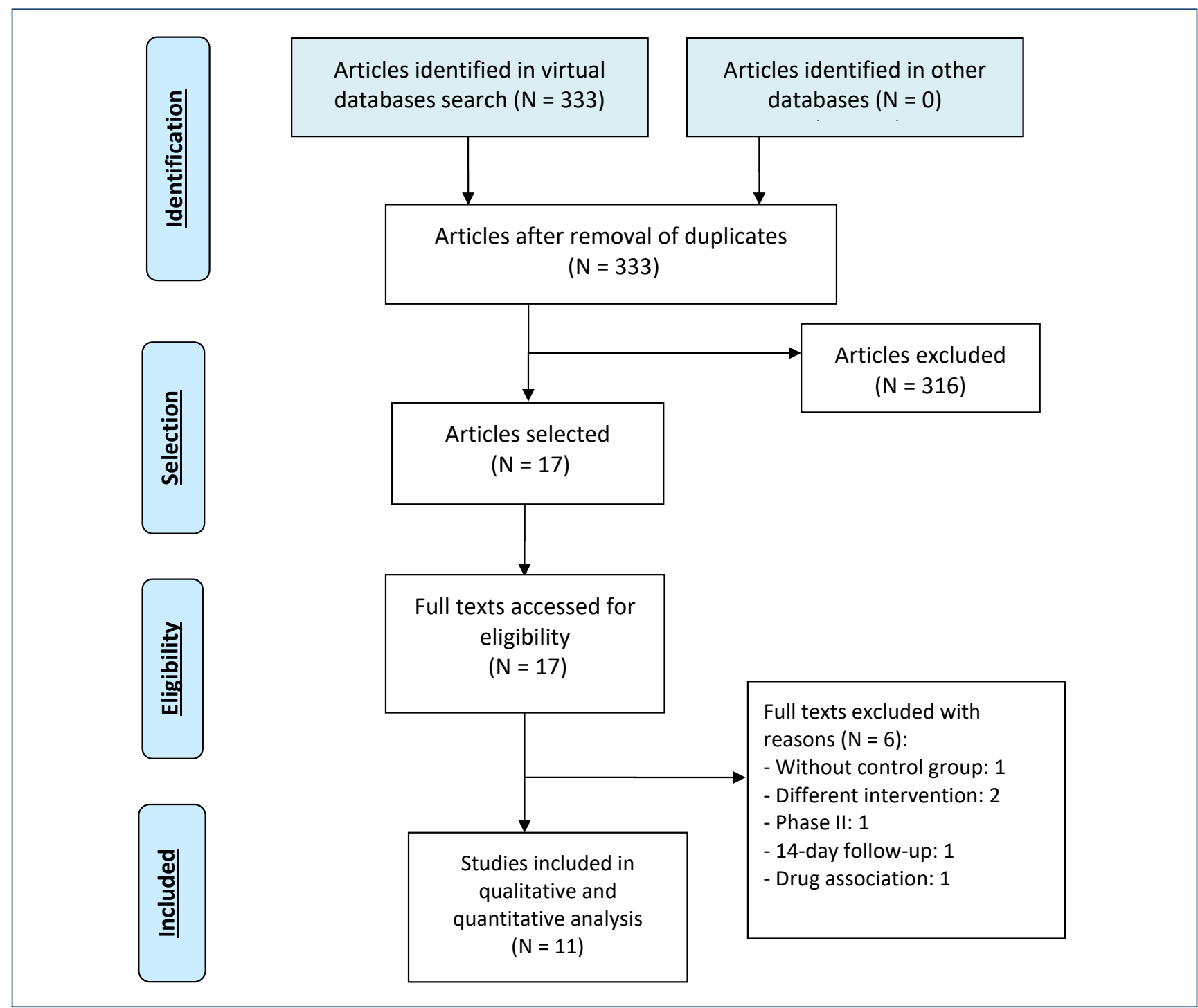

Figure 1. Evidence selection and retrieval diagram. Adapted from: Moher D, Liberati A, Tetzlaff J, Altman DG, The PRISMA Group. Preferred reporting items for systematic reviews and meta-analyses: the PRISMA statement. PLoS Med. 2009;6(7):e1000097. https://doi.org/10.1371/ journal.pmed1000097 
25 patients to be treated to avoid MV (95\%CI 25-1,000) (Figure 3). This results in low quality of evidence.

Six studies allowed us to assess the outcome of hospital discharge within 28 days, with a total of 5,743 participants. Comparing $\mathrm{TCZ}+\mathrm{SC}$ with SC alone, there was an increase of $6 \%(95 \% \mathrm{CI}$ 4-8\%) favoring the use of TCZ, being necessary to treat 16 patients (95\%CI 12-25) to obtain a hospital discharge during this period $\left(\mathrm{I}^{2}=0 \%\right.$, Figure 4$)$. This results in moderate quality of evidence.

Eight studies allowed evaluating the outcome of serious adverse events, with a total of 2,376 participants. Comparing the $\mathrm{TCZ}+\mathrm{SC}$ with SC alone, there was no difference between the two approaches (RRA $=-0.01,95 \% \mathrm{CI}-0.02$ to $0.01 ; \mathrm{I}^{2}=0 \%$ ) (Figure 5). This results in moderate quality of evidence.

\section{TOFACITINIB}

A total of 289 patients, aged $>18$ years, diagnosed with SARS$\mathrm{CoV}-19$ by polymerase chain reaction (PCR), with radiological image of bronchopneumonia, admitted for $<72 \mathrm{~h}$, were included in the study using tofacitinib. Exclusion criteria were noninvasive and invasive ventilation, extracorporeal membrane oxygenation (ECMO), history of thrombosis, immunosuppression, and cancer in current or recent treatment. A total of 144 patients received tofacitinib $(10 \mathrm{mg}$, orally, twice a day for 14 days or until hospital discharge) and 145 received placebo. The primary composite end point was respiratory failure and death, with follow-up up to 28 days. Secondary outcomes were death within 28 days, patients not using MV or ECMO, patients not hospitalized within 14 and 28 days, cure (fever resolution, cough, and no $\mathrm{O}_{2}$ support), length of hospital stay, and length of stay in the intensive care unit (ICU).

Regarding the risk of bias, assessed using the RoB version 2 tool, it was not blinded, and the outcome was composed (death and respiratory failure); thus, the risk of bias may be considered moderate.

There was an RRA, composite outcome, death, and respiratory failure, in a follow-up of up to 28 days. Also, there was an RRA of $11 \%$ (95\%CI 1-21\%), requiring nine patients to be treated for a benefit. This results in very low quality of evidence.

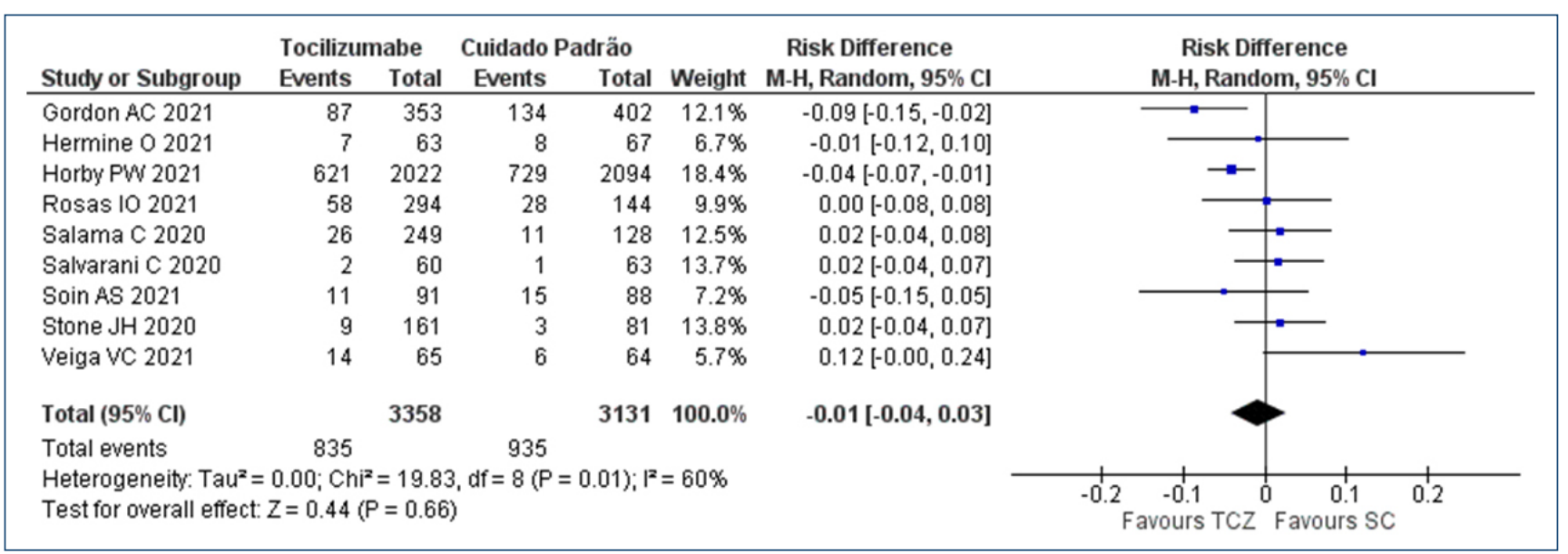

Figure 2. Tocilizumab versus standard care in the incidence of death up to 28 days.

\begin{tabular}{|c|c|c|c|c|c|c|c|c|c|c|}
\hline \multirow[b]{2}{*}{ Study or Subgroup } & \multicolumn{2}{|c|}{ Tocilizumabe } & \multicolumn{2}{|c|}{ Cuidado Padrão } & \multirow[b]{2}{*}{ Weight } & \multirow{2}{*}{$\begin{array}{c}\text { Risk Difference } \\
\text { M-H, Random, 95\% Cl }\end{array}$} & \multirow{2}{*}{\multicolumn{3}{|c|}{$\begin{array}{c}\text { Risk Difference } \\
\text { M-H, Random, } 95 \% \mathrm{Cl}\end{array}$}} & \\
\hline & Events & Total & Events & Total & & & & & & \\
\hline Horby PW 2021 & 67 & 935 & 86 & 933 & $71.0 \%$ & $-0.02[-0.05,0.00]$ & & & & \\
\hline Rosas 102021 & 51 & 183 & 30 & 90 & $3.2 \%$ & $-0.05[-0.17,0.06]$ & & & & \\
\hline Salama C 2020 & 20 & 249 & 16 & 128 & $9.9 \%$ & $-0.04[-0.11,0.02]$ & & & - & \\
\hline Salvarani C 2020 & 6 & 60 & 5 & 63 & $4.3 \%$ & $0.02[-0.08,0.12]$ & & & & \\
\hline Soin AS 2021 & 14 & 91 & 13 & 88 & $4.0 \%$ & $0.01[-0.10,0.11]$ & & & & \\
\hline Stone JH 2020 & 11 & 161 & 8 & 81 & $7.6 \%$ & $-0.03[-0.11,0.05]$ & & & & \\
\hline Total $(95 \% \mathrm{Cl})$ & & 1679 & & 1383 & $100.0 \%$ & $-0.02[-0.04,-0.00]$ & & & & \\
\hline Total events & 169 & & 158 & & & & & & & \\
\hline $\begin{array}{l}\text { Heterogeneity: Tau } \\
\text { Test for overall effec }\end{array}$ & $\begin{array}{l}0.00 ; \mathrm{Chi} \\
\mathrm{Z}=2.05\end{array}$ & $\begin{array}{l}=1.79, \\
=0.04\end{array}$ & $d f=5(P=$ & $88) ; 1^{2}=$ & $0 \%$ & & +0.2 & $\begin{array}{ll}-0.1 & 1 \\
\text { Favours } \mathrm{TCZ} & \end{array}$ & $\begin{array}{lr}0 & 0.1 \\
\text { Favours SC }\end{array}$ & 0.2 \\
\hline
\end{tabular}

Figure 3. Tocilizumab versus standard care in the incidence of mechanical ventilation up to 28 days. 


\begin{tabular}{|c|c|c|c|c|c|c|c|c|c|c|}
\hline \multirow[b]{2}{*}{ Study or Subgroup } & \multicolumn{2}{|c|}{ Tocilizumabe } & \multicolumn{2}{|c|}{ Cuidado Padräo } & \multirow[b]{2}{*}{ Weight } & \multirow{2}{*}{$\begin{array}{l}\text { Risk Difference } \\
\text { M-H, Random, } 95 \% \mathrm{Cl}\end{array}$} & \multirow{2}{*}{\multicolumn{3}{|c|}{$\begin{array}{c}\text { Risk Difference } \\
\text { M-H, Random, } 95 \% \mathrm{Cl}\end{array}$}} & \\
\hline & Events & Total & Events & Total & & & & & & \\
\hline Gordon AC 2021 & 190 & 353 & 184 & 402 & $11.4 \%$ & $0.08[0.01,0.15]$ & & & & \\
\hline Hermine 02021 & 52 & 63 & 49 & 67 & $2.9 \%$ & $0.09[-0.05,0.24]$ & & & & \\
\hline Horby PW 2021 & 1150 & 2022 & 1044 & 2094 & $62.7 \%$ & $0.07[0.04,0.10]$ & & & & \\
\hline Salama C 2020 & 216 & 249 & 107 & 128 & $9.8 \%$ & $0.03[-0.05,0.11]$ & & & & \\
\hline Salvarani C 2020 & 54 & 60 & 58 & 63 & $5.7 \%$ & $-0.02[-0.12,0.08]$ & & & & \\
\hline Stone $\mathrm{JH} 2020$ & 145 & 161 & 70 & 81 & $7.5 \%$ & $0.04[-0.05,0.12]$ & & & & \\
\hline Total $(95 \% \mathrm{Cl})$ & & 2908 & & 2835 & $100.0 \%$ & $0.06[0.04,0.08]$ & & & & \\
\hline Total events & 1807 & & 1512 & & & & & & & \\
\hline \multicolumn{7}{|c|}{$\begin{array}{l}\text { Heterogeneity: } \mathrm{Tau}^{2}=0.00 ; \mathrm{Chi}^{2}=4.46, \mathrm{df}=5(\mathrm{P}=0.49) ; \mathrm{I}^{2}=0 \% \\
\text { Test for overall effect: } Z=4.93(P<0.00001)\end{array}$} & -0.2 & $\begin{array}{c}-0.1 \\
\text { Favours SC }\end{array}$ & $\begin{array}{cc} & 1 \\
& 0.1 \\
\text { Favours TCZ }\end{array}$ & ${ }^{1} \cdot 2$ \\
\hline
\end{tabular}

Figure 4. Tocilizumab versus standard care in the incidence of hospital discharge within 28 days.

\begin{tabular}{|c|c|c|c|c|c|c|c|}
\hline Study or Subgroup & \multicolumn{2}{|c|}{ Tocilizumabe } & \multicolumn{2}{|c|}{ Cuidado Padrão } & Weight & $\begin{array}{c}\text { Risk Difference } \\
\text { M-H, Random, } 95 \% \mathrm{Cl}\end{array}$ & $\begin{array}{c}\text { Risk Difference } \\
\text { M-H, Random, } 95 \% \mathrm{Cl}\end{array}$ \\
\hline Gordon AC 2021 & 9 & 353 & 11 & 403 & $68.1 \%$ & $-0.00[-0.02,0.02]$ & \\
\hline Hermine 02021 & 20 & 63 & 29 & 67 & $1.3 \%$ & $-0.12[-0.28,0.05]$ & \\
\hline Rosas 102021 & 103 & 295 & 55 & 143 & $3.8 \%$ & $-0.04[-0.13,0.06]$ & \\
\hline Salama C 2020 & 38 & 250 & 25 & 127 & $5.3 \%$ & $-0.04[-0.13,0.04]$ & - \\
\hline Salvarani C 2020 & 1 & 60 & 2 & 63 & $12.2 \%$ & $-0.02[-0.07,0.04]$ & . \\
\hline Soin AS 2021 & 15 & 91 & 15 & 89 & $3.0 \%$ & $-0.00[-0.11,0.11]$ & \\
\hline Stone JH 2020 & 28 & 161 & 12 & 82 & $3.8 \%$ & $0.03[-0.07,0.12]$ & \\
\hline Veiga VC 2021 & 11 & 65 & 7 & 64 & $2.5 \%$ & $0.06[-0.06,0.18]$ & \\
\hline Total $(95 \% \mathrm{Cl})$ & & 1338 & & 1038 & $100.0 \%$ & $-0.01[-0.02,0.01]$ & \\
\hline Total events & 225 & & 156 & & & & \\
\hline \multicolumn{7}{|c|}{$\begin{array}{l}\text { Heterogeneity: } \operatorname{Tau}^{2}=0.00 ; \mathrm{Chi}^{2}=5.70, \mathrm{df}=7(P=0.58) ; \mathrm{I}^{2}=0 \% \\
\text { Test for overall effect: } Z=0.61(P=0.54)\end{array}$} & $\begin{array}{ccccc}1 & 1 & 1 & 1 \\
-0.2 & -0.1 & 0 & 0.1 & 0.2 \\
\text { Favours } \mathrm{TCZ} & \text { Favours SC }\end{array}$ \\
\hline
\end{tabular}

Figure 5. Tocilizumab versus standard care in the incidence of serious adverse events up to 28 days.

Regarding the death within 28 days outcome, there was no significant RRA (3\%) (95\%CI -7 to 2\%). This results in low quality of evidence.

In the evaluation of serious adverse events, there was no difference between the two groups (2\%) (95\%CI -6 to $10 \%)$. This results in low quality of evidence.

\section{BARICITINIB}

In this multicenter, randomized, double-blind, placebo-controlled, parallel-group, phase 3 study, eligible participants were at least 18 years of age, were hospitalized with laboratory-confirmed SARS-CoV-2 infection, and had evidence of pneumonia or COVID-19 active and symptomatic. Participants were excluded if, at baseline, they required invasive MV.

Randomization was facilitated by a computer-generated random sequence using a web-interactive response system and was allowed by a study investigator to allocate 1:1 participant to the baricitinib group or the placebo group. Interventions were allocated to identical bottles containing $2 \mathrm{mg}$ baricitinib tablets (total of $4 \mathrm{mg}$ ) or matching placebo. Baricitinib tablets or placebo were administered orally (or crushed for administration by nasogastric tube) and administered daily for up to 14 days or until hospital discharge.

The primary composite end point was the proportion of participants who progressed to high-flow oxygen or noninvasive ventilation, invasive MV or ECMO, or death at day 28 in the baricitinib group compared with the placebo group.

Baseline demographics and disease characteristics were similar between study groups. Of the 1,502 participants, 1,248 (83.1\%) completed the 28-day treatment period and 254 (16.9\%) discontinued treatment during this period, of which $159(62.6 \%)$ died.

There was a $5 \%$ reduction in the risk of death, ranging from 2 to $8 \%$, being necessary to treat 20 patients for a benefit, ranging from 12 to 50 . There were 62 deaths in 764 patients on 
baricitinib ( $8 \%$ risk of death with baricitinib) and 100 deaths in 761 patients in the placebo group (13\% risk of death). This results in low quality of evidence.

Regarding adverse events, 334 (45\%) of 750 participants in the baricitinib group and 334 (44\%) of 752 in the placebo group had at least one treatment-emergent adverse event, and serious adverse events were noted in 110 (15\%) participants in the baricitinib group and 135 (18\%) in the placebo group. This results in low quality of evidence.

The risk of bias is serious when losses occur due to death in patients who were not submitted to the treatment protocol, but who were included in the mortality outcome. Losses due to death were uneven (unbalanced) between the two groups (7.9\% for baricitinib and $12.8 \%$ for placebo). In addition, the analysis by intention (for mortality) of treatment was inappropriate as it considered the losses due to death in the risk calculation, as well as the expression of benefit was expressed by hazard ratio (HR) and not by RD (RRA), thus increasing the magnitude of the benefit.

\section{REFERENCES}

1. Review Manager (RevMan) [Computer program]. Version 5.4. The Cochrane Collaboration, 2020.

2. Sterne JAC, Savović J, Page MJ, Elbers RG, Blencowe NS, Boutron I, et al. RoB 2: a revised tool for assessing risk of bias in randomised trials. BMJ. 2019:366:14898. https://doi.org/10.1136/bmj.|4898

3. GRADEpro GDT: GRADEpro Guideline Development Tool [Software]. McMaster University, 2020 (developed by Evidence Prime, Inc.). Available from gradepro.org.

4. REMAP-CAP Investigators, Gordon AC, Mouncey PR, Al-Beidh F, Rowan KM, Nichol AD, et al. Interleukin-6 receptor antagonists in criticallyill patients with Covid-19.NEngl J Med.2021;384(16):1491502. https://doi.org/10.1056/NEJMoa2100433

5. Hermine $O$, Mariette $X$, Tharaux PL, Resche-Rigon M, Porcher $\mathrm{R}$, Ravaud $\mathrm{P}$, et al. Effect of tocilizumab vs usual care in adults hospitalized with COVID-19 and moderate or severe pneumonia: a randomized clinical trial. JAMA Intern Med. 2021;181(1):32-40. https://doi.org/10.1001/jamainternmed.2020.6820. Erratum in: JAMA Intern Med. 2021;181(1):144

6. RECOVERY Collaborative Group. Tocilizumab in patients admitted to hospital with COVID-19 (RECOVERY): a randomised, controlled, open-label, platform trial. Lancet. 2021;397(10285):1637-45. https://doi.org/10.1016/S0140-6736(21)00676-0

7. Rosas IO, Bräu N, Waters M, Go RC, Hunter BD, Bhagani S, et al. Tocilizumab in hospitalized patients with severe Covid-19 pneumonia. N Engl J Med. 2021;384(16):1503-16. https://doi. org/10.1056/NEJMoa2028700

8. Salama C, Han J, Yau L, Reiss WG, Kramer B, Neidhart JD, et al. Tocilizumab in patients hospitalized with Covid-19 pneumonia. N Engl J Med. 2021;384(1):20-30. https://doi.org/10.1056/ NEJMoa2030340

\section{RECOMMENDATION}

In patients hospitalized with COVID-19:

- The use of TCZ can reduce the risk of needing MV $(2 \%)$ and increase the rate of hospital discharge (6\%); however, there was no significant RRA of death.

- There is no benefit from using tofacitinib.

- The use of baricitinib can reduce mortality by $5 \%$.

The quality of evidence to support these recommendations is low.

\section{AUTHORS' CONTRIBUTION}

SET, HB, ANB, and WMB: study concept and design. WMB, SET, AS and IF: data collection, statistical analyses and interpretation of data. WMB, IF, AS and SET: drafting of the manuscript. SET, HAB, ANB, and WMB: critical review and approval of the final version.

9. Salvarani C, Dolci G, Massari M, Merlo DF, Cavuto S, Savoldi L, et al. Effect of tocilizumab vs standard care on clinical worsening in patients hospitalized with COVID-19 pneumonia: a randomized clinical trial. JAMA Intern Med. 2021;181(1):24-31. https://doi. org/10.1001/jamainternmed.2020.6615

10. Soin AS, Kumar K, Choudhary NS, Sharma P, Mehta Y, Kataria $\mathrm{S}$, et al. Tocilizumab plus standard care versus standard care in patients in India with moderate to severe COVID-19associated cytokine release syndrome (COVINTOC): an openlabel, multicentre, randomised, controlled, phase 3 trial. Lancet Respir Med. 2021;9(5):511-21. https://doi.org/10.1016/S22132600(21)00081-3

11. Stone JH, Frigault MJ, Serling-Boyd NJ, Fernandes AD, Harvey L, Foulkes AS, et al. Efficacy of tocilizumab in patients hospitalized with Covid-19. N Engl J Med. 2020;383(24):2333-44. https://doi. org/10.1056/NEJMoa2028836

12. Veiga VC, Prats JAGG, Farias DLC, Rosa RG, Dourado LK, Zampieri FG, et al. Effect of tocilizumab on clinical outcomes at 15 days in patients with severe or critical coronavirus disease 2019 : randomised controlled trial. BMJ. 2021;372:n84. https://doi.org/ 10.1136/bmj.n84

13. Guimarães PO, Quirk D, Furtado RH, Maia LN, Saraiva JF, Antunes $\mathrm{MO}$, et al. Tofacitinib in patients hospitalized with Covid-19 pneumonia. N Engl J Med. 2021;385(5):406-15. https://doi. org/10.1056/NEJMoa2101643

14. Marconi VC, Ramanan AV, Bono S, Kartman CE, Krishnan V, Liao $R$, et al. Efficacy and safety of baricitinib for the treatment of hospitalised adults with COVID-19 (COV-BARRIER): a randomised, double-blind, parallel-group, placebo-controlled phase 3 trial. Lancet Respir Med. 2021:9(12):1407-18. https://doi.org/10.1016/ S2213-2600(21)00331-3. Epub ahead of print. Erratum in: Lancet Respir Med. 2021. 